\title{
Pembuatan Game Online BoMCleaN sebagai Media Pembelajaran Kebersihan Lingkungan
}

\author{
Sussi $^{\# 1}$, Rendy Munadi ${ }^{\# 2}$, Rahmat Ramadan Prasojoe ${ }^{* 3}$, Nurwulan Fitriyanti ${ }^{\# 4}$, Kusviwahan Muhammad \\ Shihab $^{\# 5}$, \\ ${ }^{\#}$ Fakultas Teknik Elektro, Universitas Telkom \\ ${ }^{1}$ sussiss@telkomuniversity.ac.id \\ ${ }^{2}$ rendymunadietelkomuniversity.ac.id \\ ${ }^{4}$ nurwulanfetelkomuniversity.ac.id \\ ${ }^{5}$ kusvihawan@telkomuniversity.ac.id \\ "Fakultas Teknik Informatika \\ Jl.Telekomunikasi No.1 \\ prasojoe@telkomuniversity.ac.id
}

\begin{abstract}
Abstrak - Perkembangan video game saat ini sangatlah pesat dan sudah beredar dalam berbagai genre permainan seperti aksi, horror, pertualangan, puzzle dan game online. Seiring dengan perkembangan jaringan internet maka game online juga ikut berkembang dan mampu menarik banyak orang untuk memainkannya. Kebanyakan video game yang dibuat hanya ditujukan untuk menghabiskan waktu dan menghibur player agar jauh dari kebosanan. Pelajaran tentang kebersihan lingkungan perlu diajarkan sejak dini sehingga mampu membawa perubahan, baik berupa pengetahuan maupun tingkah laku. BoMCleaN adalah sebuah video game yang ditujukan untuk menghibur serta menambah kesadaran tentang pentingnya menjaga kebersihan lingkungan sambil bermain dengan pemain lainnya menggunakan konsep multiplayer. Fitur utama dalam video game BoMCleaN menantang pemain menempatkan sampah pada tempatnya yang tepat. BoMCleaN menjadi salah satu Media Pembelajaran Kebersihan Lingkungan (PKL) yang mampu menambah pengetahuan akan pengklasifikasian sampah.
\end{abstract}

Kata kunci- Video Game, Game Online, Multiplayer, Genre, Networking

\section{PENDAhUluan}

Negara Indonesia memiliki UU No 23 Tahun 1999 yang menerangkan tentang usaha untuk mewujudkan masyarakat yang sehat. Berdasarkan undang-undang tersebut negara memiliki kewajiban untuk menciptakan lingkungan yang sehat bagi warganya. Upaya yang dilakukan oleh pemerintah yaitu dengan mengkampanyekan pola hidup bersih dan sehat (PHBS) melalui berbagai program penyuluhan. Beberapa hambatan yang terjadi saat PHBS yaitu lokasi daerah penyuluhan yang sulit dijangkau, media penyuluhan yang tidak interaktif serta tidak menarik untuk memahami kebersihan lingkungan. Maka dari itu dibutuhkan media pembelajaran kebersihan lingkungan yang mampu menarik berbagai kalangan terutama kalangan anak, mudah diakses, menghibur dan tetap memberikan pengetahuan akan kebersihan.

Video game merupakan salah satu sarana hiburan yang saat ini digunakan oleh banyak orang. Bukan hanya sarana hiburan, video game juga dapat digunakan untuk sarana pembelajaran dan mengasah kemampuan berpikir pemain. Penggunaan game console sudah mulai berkurang, arah perkembangan game saat ini menyasar pada pengguna perangkat komunikasi bergerak seperti smartphone dan komputer dengan jaringan internet. Hal ini sering disebut dengan istilah game online.

Perancangan video game BoMCleaN dilatar belakangi oleh kepopuleran game online atau game multiplayer dikalangan pemain serta sedikitnya game yang mendidik untuk anak-anak, kurangnya kesadaran masyarakat akan pentingnya kebersihan lingkungan mereka dan diperlukan metode baru dalam penyampaian PHBS. Dari keempat faktor tersebut diharapkan pemain memiliki wawasan tambahan dan kesadaran mengenai perlunya menjaga kebersihan lingkungan dengan menikmati game BoMCleaN. Video game BoMCleaN merupakan permainan yang menguji daya kompetisi satu pemain dengan pemain lainnya karena sifatnya multiplayer, dapat dimainkan lebih dari satu pemain.

\section{TINJAUAN PUSTKA}

\section{A. Game}

Game merupakan salah satu media yang dapat digunakan dalam menyampaikan sebuah tujuan antara lain untuk pendidikan, hiburan dan simulasi. Dalam sejarah kehidupan manusia, game selalu ada dan terus diminati oleh berbagai kalangan disegala usia. Keberadaannya begitu ditunggu untuk melepaskan rasa penat setelah 
seharian belajar ataupun bekerja. Selain itu, game juga telah mengisi masa kecil setiap orang sehingga menjadi nostalgia tersendiri ketika game dimainkan kembali.

Game sudah ada sejak beribu-ribu tahun yang lalu dalam bentuk permainan tradisional. Di berbagai negara, terdapat permainan tradisional tersendiri sesuai dengan budaya masing-masing negara. Seiring dengan perkembangan jaman game diklasifikasikan berdasarkan tujuannya sebagaimana dalam [8] yakni:

1. Game as Game, game yang dimaksud adalah game untuk kesenangan.

2. Game as Media, game untuk menyampaikan pesan dari pembuat game.

3. Game Beyond Game, dikenal juga dengan istilah gamification. Gamification adalah penerapan konsep atau cara berpikir game design ke dalam lingkup non-game.

\section{B. Video game}

Video game adalah game yang menggunakan interaksi dengan antarmuka pengguna melalui gambar yang dihasilkan oleh piranti video. Game umumnya menyediakan sistem penghargaan misalnya skor, yang dihitung berdasarkan tingkat keberhasilan yang dicapai dalam menyelesaikan tugas yang ada di dalam permainan. Kata video pada video game pada awalnya merujuk pada piranti tampilan raster. Seiring perjalanan waktu istilah video game dapat digunakan untuk menyebut game pada piranti tampilan apapun atau sistem elektronik yang disebut platform [6].

Berbagai jenis platform yang digunakan dalam pengembangan game sebagaimana dalam [8] adalah sebagai berikut:

1. Arcade games yang sering disebut ding-dong di Indonesia, biasanya berada di tempat khusus, memiliki mesin yang memang khusus di desain untuk jenis game tertentu dan tidak jarang memiliki fitur yang dapat membuat pemainnya lebih merasa "masuk" dan "menikmati" seperti adanya pistol, kursi khusus, sensor gerakan, sensor injakkan dan stir mobil.

2. PC Games, video game yang dimainkan menggunakan personal computer.

3. Console games, yaitu video game yang dimainkan menggunakan console tertentu, seperti Playstation 2, Playstation 3, XBOX 360 dan Nintendo Wii.

4. Handheld games, video game yang dimainkan di console khusus sehingga dapat dibawa kemana-mana contoh Nintendo DS dan Sony PSP.

5. Mobile games, video game yang dapat dimainkan atau khusus untuk mobile phone atau PDA.

\section{Game Online}

Perkembangan game online tidak lepas dari teknologi komputer dan jaringan komputer itu sendiri. Meledaknya game online merupakan cerminan dari pesatnya jaringan komputer yang dahulunya berskala kecil (small local network) sampai menjadi internet dan terus berkembang sampai sekarang. Pada saat muncul pertama kalinya, pada tahun 1996, komputer hanya bisa dipakai untuk dua orang saja dalam bermain game. Seiring perjalanan lahirlah komputer dengan kemampuan time-sharing sehingga pemain yang bisa memainkan game tersebut bisa lebih banyak dan tidak harus berada pada dalam satu ruangan yang sama (Multiplayer Games) [12].

Game online bisa disebut sebagai bagian dari aktivitas sosial karena pemain bisa saling berinteraksi secara virtual dan seringkali menciptakan komunitas maya. Sebagaimana dalam [3] game online berdasarkan jenisnya diklasifikasikan menjadi tujuh yaitu: Massively Multiplayer Online Firstperson shooter games (MMOFPS), Massively Multiplayer Online Real-time strategy games (MMORTS), Massively Multiplayer Online Roleplaying games (MMORPG), Cross-platform online play, Massively Multiplayer Online Browser Game, Simulation games, Massively multiplayer online games (MMOG) .

\section{Game Edukasi}

Kuswardayan (2012: 255) menjelaskan bahwa game edukasi merupakan suatu permainan yang berusaha memberikan nilai edukasi sehingga permainan yang awalnya hanya berfungsi sebagai media hiburan dapat juga digunakan sebagai media pembelajaran. Salah satu kelebihan dari game edukasi terletak pada visualisasi permasalahan dilingkungan. Massachussets Insitute of Technology (MIT) berhasil membuktikan bahwa game sangat berguna untuk meningkatkan logika dan pemahaman pemain terhadap suatu masalah melalui proyek game yang dinamai Scratch.

Game edukasi unggul dalam beberapa aspek jika dibandingkan dengan metode pembelajaran konvensional. Salah satu keunggulan yang signifikan adalah adanya animasi yang dapat meningkatkan daya ingat sehingga anak dapat menyimpan materi pelajaran dalam waktu yang lebih lama dibandingkan dengan metode pembelajaran konvensional.

Kekurangan game edukasi terletak pada minat masyarakat yang masih rendah dan apabila orang mendengar kata game edukasi mereka akan langsung berpikiran bahwa game tersebut membosankan dan tidak menarik, Dan hal ini telah menjadi mindset masyarakat sejak game edukasi itu pertama kali muncul.

\section{METODE PENELITIAN}

System Development Life Cycle (SDLC) merupakan suatu urutan dari beberapa proses secara bertahap didalam merancang dan mengembangkan sistem yang dikenal juga dengan nama Information System Development atau juga Application Development [4]. Pembuatan video game BoMCleaN menggunakan metode pengembangan System Development Life Cycle dimulai dari analisis, perancangan, pembuatan, pengujian, development. 


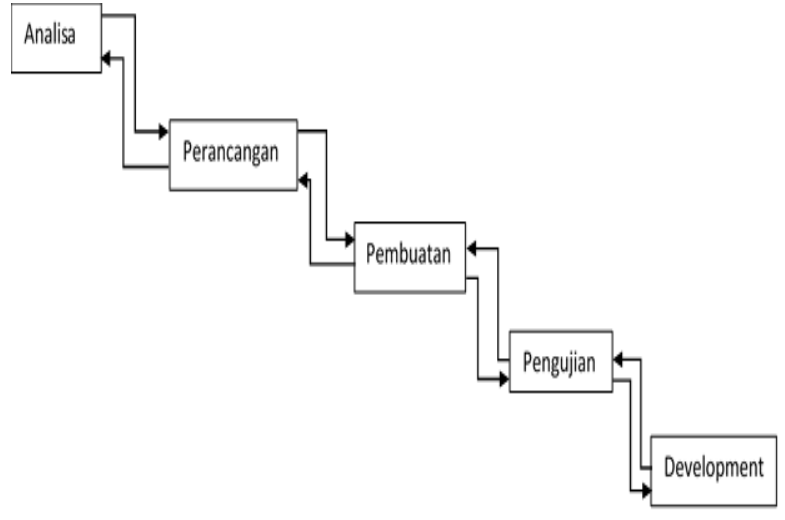

Gambar. 1 Metode System Developmet Life Cylce (SDLC) Waterfall dalam Pengembangan Game BoMCleaN

\section{A. Tahapan Analisa}

Pada tahap analisa developer mencari data dan informasi yang diperlukan untuk membangun game online yang menarik dan cocok dengan ide utama yaitu game online bertemakan kebersihan lingkungan.

\section{B. Tahapan Perancangan}

Pada tahap perancangan, developer mulai merancang secara detail bagaimana video game tersebut akan dibangun mulai dari networking, gameplay, art yang telah di analisa pada tahap sebelumnya. Adapun beberapa rincian perancangan video game sebagai berikut.

\section{1) Deskripsi Permainan}

BoMCleaN adalah sebuah permainan dengan konsep dapat dimainkan lebih dari satu pemain (multiplayer). Game ini bertema tentang pentingnya kebersihan lingkungan, dimana setiap pemain bertanding dengan pemain lain untuk memperebutkan score yang lebih tinggi.

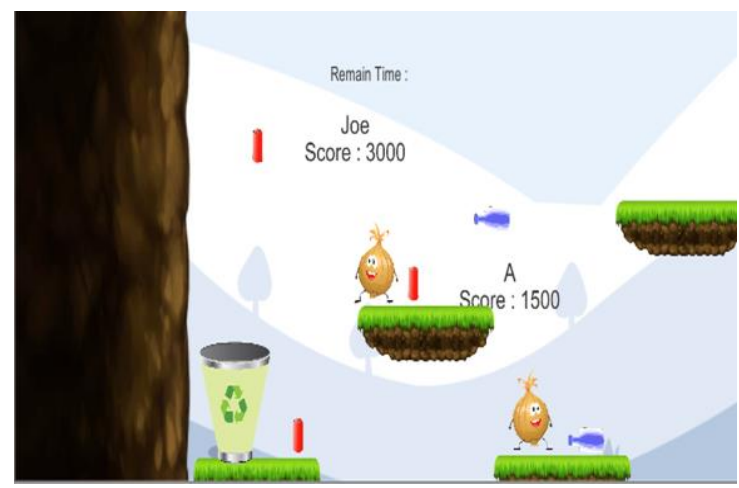

Gambar. 2 Game BoMCleaN dimainkan dengan konsep multiplayer

Pemain dapat menggerakkan karakter ke kiri, ke kanan, dan lompat. Demi mendapatkan score, pemain harus mengambil sampah yang terjatuh dan membuangnya ke tempat sampah yang telah disediakan. Beberapa sampah memiliki keunikan diantaranya ada sampah yang hanya bisa dibuang ke tempat sampah tertentu. Sampah kertas dan organik hanya bisa dibuang ke burnable basket dan sampah kaleng dan botol plastik hanya dapat dibuang ke recycleable basket.

Jika pemain mengambil sampah dan membuangnya ke tempat sampah yang benar, pemain akan mendapatkan penambahan score jika sebaliknya maka pemain tidak mendapatkan penambahan score. Dalam batas waktu tertentu para pemain saling bersaing demi mendapatkan score yang paling tinggi.

\section{2) Konsep Permainan}

Permainan ini menggunakan konsep platform slide dimana pemain akan memainkan sebuah karakter yang dapat bergerak dari kiri ke kanan. Tujuan dari permainan ini adalah untuk mengambil sampah yang terjatuh dan membuangnya ke tempat sampah yang telah disediakan untuk mendapatkan penambahan score. Tantangan dari permainan BoMCleaN adalah setiap pemain besaing untuk memperoleh score tertinggi.

TABEL I

PENGENALAN KARAKTER

\begin{tabular}{|l|l|l|}
\hline No & \multicolumn{1}{c|}{ Keterangan } \\
\hline 1. & $\begin{array}{l}\text { Pemain } \\
\text { Bisa bergerak keatas } \\
\text { kebawah (lompat), kekiri } \\
\text { kekanan untuk } \\
\text { mengambil sampah dan } \\
\text { memasukannya kedalam } \\
\text { tempat sampah. } \\
\text { Karakter pemain sama } \\
\text { walau dijalankan oleh } \\
\text { beberapa pemain. } \\
\text { Pemain satu dan lainnya } \\
\text { dibedakan dengan } \\
\text { penulisan nama diatas } \\
\text { karakter pemain. }\end{array}$ \\
\hline 2. & $\begin{array}{l}\text { Pemain } \\
\text { Pemain sudah berhasil } \\
\text { mengambil sampah } \\
\text { kertas dan organik. }\end{array}$ \\
\hline 3. & $\begin{array}{l}\text { Sampah non-organik, } \\
\text { kaleng dan botol plastik } \\
\text { yang diperebutkan } \\
\text { pemain untuk dibuang } \\
\text { ketempat sampah yang } \\
\text { sesuai. }\end{array}$ \\
\hline
\end{tabular}




\begin{tabular}{|l|c|l|}
\hline No & Gambar & \multicolumn{1}{c|}{ Keterangan } \\
\hline 5. & $\begin{array}{l}\text { Sampah } \\
\text { Sampah organik dan } \\
\text { sampah kertas yang } \\
\text { diperebutkan pemain } \\
\text { untuk dibuang ketempat } \\
\text { sampah yang sesuai. }\end{array}$ \\
\hline 6. & $\begin{array}{l}\text { Recycleable Basket } \\
\text { Tempat sampah untuk } \\
\text { membuang sampah } \\
\text { kaleng, botol dan non- } \\
\text { organik. }\end{array}$ \\
\hline 7. & $\begin{array}{l}\text { Burnable Basket } \\
\text { Tempat sampah untuk } \\
\text { membuang sampah } \\
\text { kertas dan organik. }\end{array}$ \\
\hline
\end{tabular}

3) Deskripsi Alur Permainan

Gambar 3 menujukkan use case diagram yang menggambarkan interaksi pemain dengan sistem game BoMCleaN secara umum.

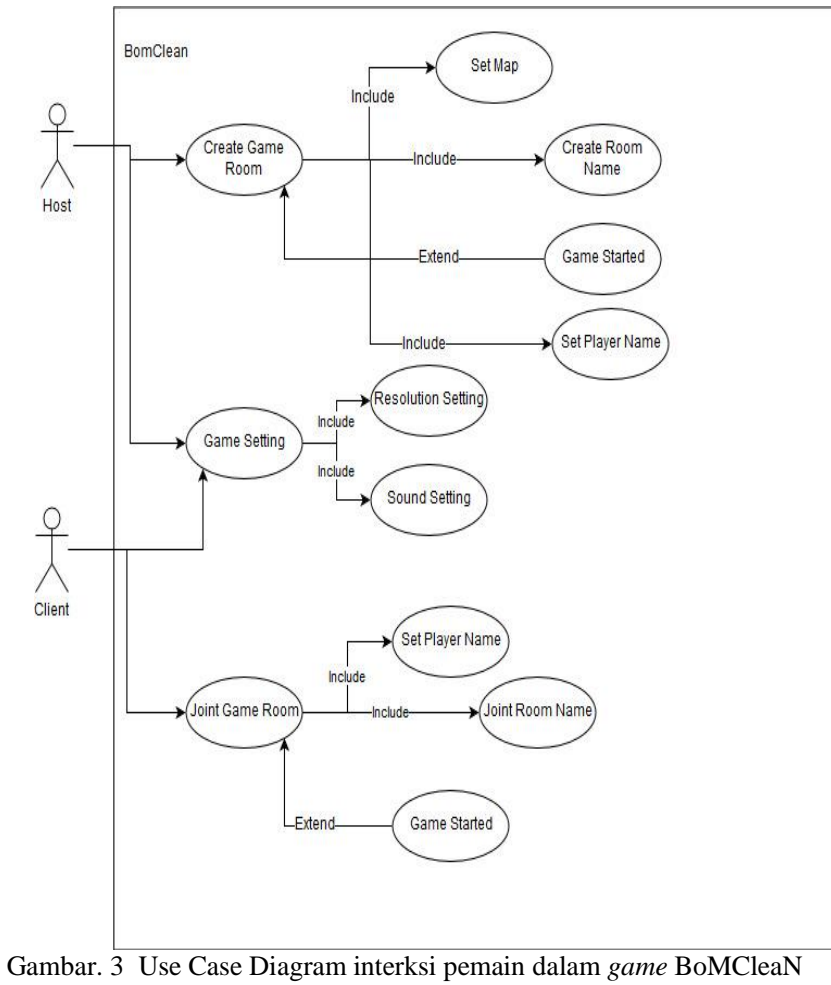

Game BoMCleaN memiliki dua tipe actor atau pemain yaitu yang bertindak sebagai host dan client. Pemain yang bertindak sebagai host dapat membuat sesi game baru dengan pengaturan yang pemain inginkan. Pemain yang bertindak sebagai client dapat memasuki sesi game yang telah dibuat oleh host dengan cara memasukkan nama room.
Penjelasan singkat dari alur game BoMCleaN adalah sebagai berikut :

a. Game diawali dengan munculnya main menu.

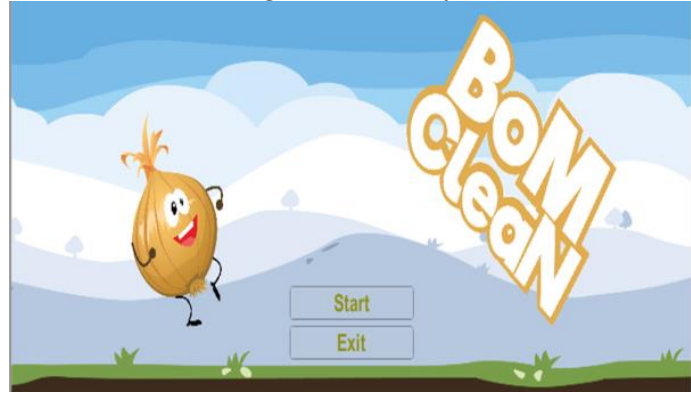

Gambar. 4 Main Menu dalam game BoMCleaN

b. Dari main menu pemain dapat memilih apakah ingin keluar dari game atau masuk ke menu matchmaking.

c. Dalam menu matchmaking terdapat 2 pilihan yaitu join room atau create room. Join room berfungsi untuk masuk ke room yang tersedia sedangkan create room berfungsi untuk membuat room baru.

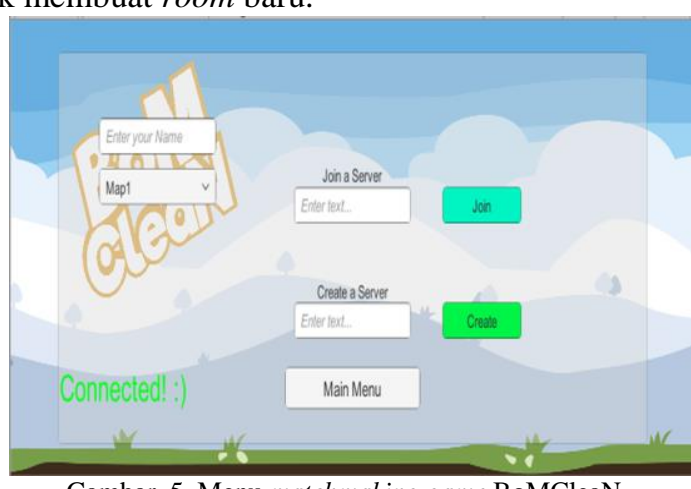

Gambar. 5 Menu matchmaking game BoMCleaN

d. Jika ingin join room maka masukkan nama room dan pilih map. Setelah itu klik tombol join room.

e. Jika ingin membuat room baru maka masukan nama room dan pilih map. Setelah itu klik tombol create room.

f. Jika berhasil maka pemain akan masuk kedalam map yang dipilih sebelumnya.

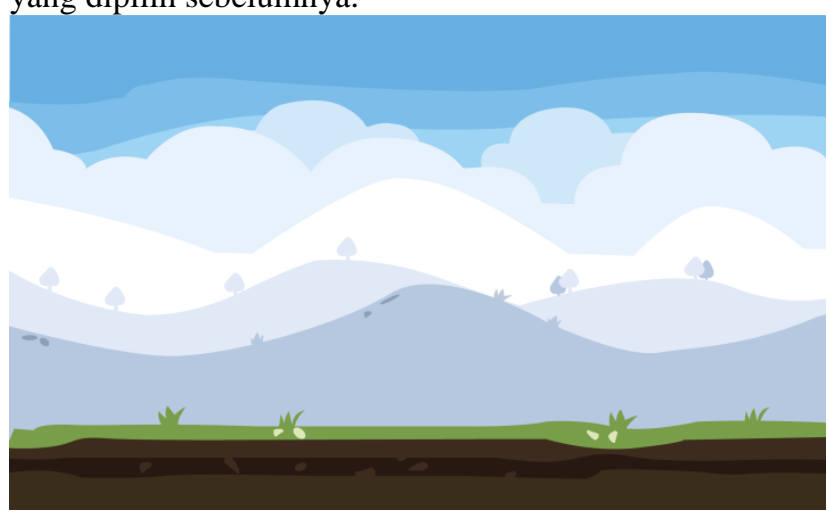

Gambar. 6 Pilihan Map 1 pada game BoMCleaN 


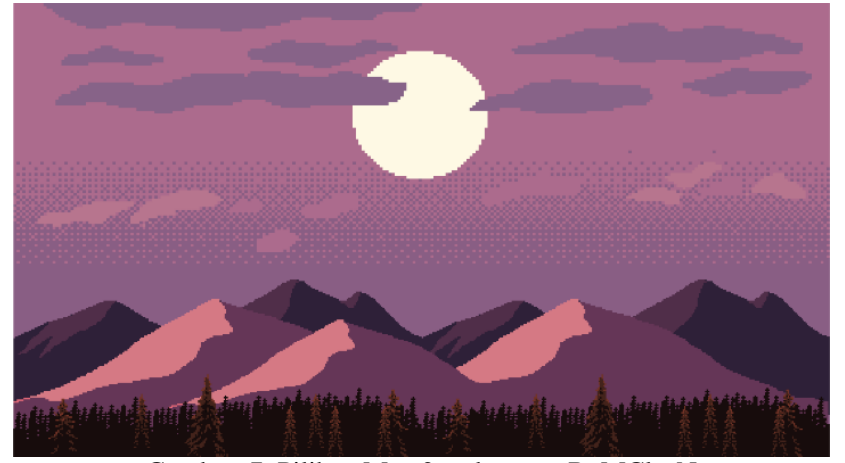

Gambar. 7 Pilihan Map 2 pada game BoMCleaN

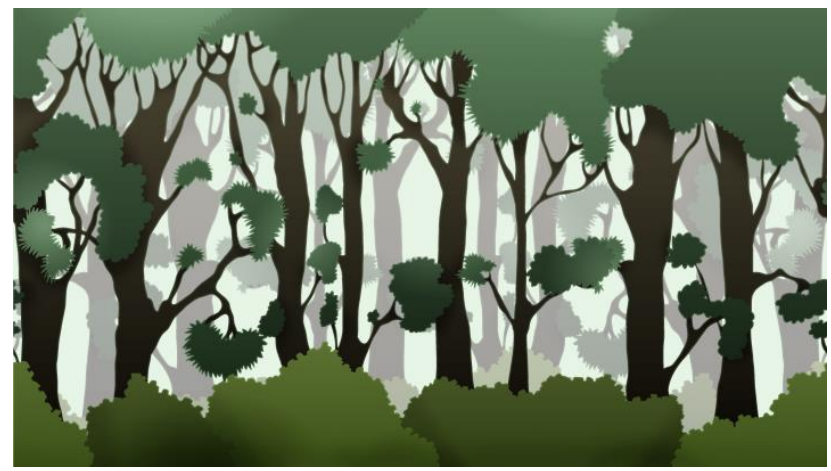

Gambar. 8 Pilihan Map 3 pada game BoMCleaN

g. Jika belum ada pemain lain yang berada didalam room tersebut. Pemain awal harus menunggu pemain lain terlebih dahulu sebelum permainan dimulai.

h. Jika pemain lain sudah ada didalam room maka permainan akan langsung dimulai.

i. Permainan berlangsung selama beberapa menit.

j. Setelah waktu habis maka akan muncul score board dimana akan menampilkan score para pemain yang sedang berada pada room tersebut.

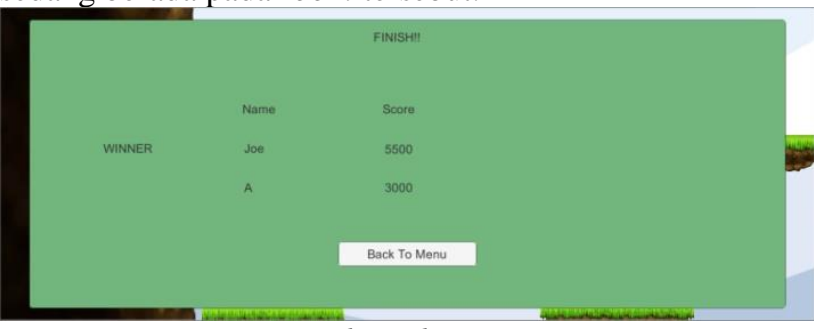

Gambar. 9 Score board pada game BoMCleaN

k. Setelah game selesai, pemain dapat memilih untuk kembali ke menu matchmaking atau ke main menu.

\section{Tahap Pembuatan}

Pada tahap pembuatan, developer mulai mengimplementasikan pembuatan game berdasarkan rancangan yang telah dibuat pada tahap sebelumnya. Developer mulai melakukan coding game, desain art game, sound engine, dll. Berbagai tools yang digunakan untuk membuat game BoMCleaN antara lain Unity Game Engine, Sound Editor, Photoshop dan Corel. Semua tools akan digunakan untuk membuat suatu game yang utuh.

\section{Tahap Pengujian}

Pada tahap pengujian, developer melakukan pengujian apakah ada bug atau tidak selama pemain menjalankan game BoMCleaN. Setelah itu, developer memperhatikan dengan seksama bug tersebut agar bisa di developed.

\section{E. Tahap Development}

Pada tahap development, developer akan mengubah beberapa user interface (UI) dan menambahkan beberapa fitur agar lebih menarik untuk di release. Release dilakukan bertahap untuk mendapatkan data-data dari pemain dan developer dapat memperbaikinya.

\section{HASIL DAN PEMBAHASAN}

Keseluruhan kebutuhan input dan system sudah terpenuhi. Game BoMCleaN hanya memiliki kendala di bagian networking dimana latency game BoMCleaN belum sepenuhnya stabil dan menyebabkan pemain mengalami disconnect secara tiba-tiba pada saat bermain.

TABEL II

PENGUJIAN INPUTAN GAME BOMCLEAN

\begin{tabular}{|l|l|l|}
\hline \multicolumn{3}{|c|}{ Pengujian Inputan } \\
\hline \multicolumn{1}{|c|}{ Deskripsi } & Inputan & Hasil \\
\hline Lompat & W, Space & Berhasil \\
\hline Gerak ke kiri & A & Berhasil \\
\hline Gerak ke kanan & D & Berhasil \\
\hline
\end{tabular}

TABEL III

PENGUJIAN SISTEM GAME BOMCLEAN

\begin{tabular}{|c|c|c|}
\hline \multicolumn{3}{|c|}{ Pengujian Sistem } \\
\hline Deskripsi & Output yang diharapkan & Hasil \\
\hline $\begin{array}{l}\text { Memulai } \\
\text { Game }\end{array}$ & $\begin{array}{l}\text { Saat game pertama kali } \\
\text { dijalankan akan mengarah } \\
\text { ke title screen }\end{array}$ & Berhasil \\
\hline $\begin{array}{l}\text { Memilih } \\
\text { Map }\end{array}$ & $\begin{array}{l}\text { Pemain memilih map saat } \\
\text { sebelum masuk kedalam } \\
\text { room }\end{array}$ & Berhasil \\
\hline $\begin{array}{l}\text { Join/Create } \\
\text { Room }\end{array}$ & $\begin{array}{l}\text { Pemain dapat masuk atau } \\
\text { membuat room }\end{array}$ & Berhasil \\
\hline Gameplay & $\begin{array}{l}\text { Pemain dapat memainkan } \\
\text { game tampa adanya } \\
\text { kendala }\end{array}$ & $\begin{array}{lr}\text { Berhasil dengn } \\
\text { networking } & \text { yang } \\
\text { bagus. } & \end{array}$ \\
\hline
\end{tabular}

Lima belas orang dewasa pernah memainkan game BoMCleaN dan mengisi kuesioner mengenai kualitas game. Responden yang memainkan game BoMCleaN terdiri dari kalangan ibu rumah tangga, wanita karir dan mahasiswa yang sudah memasuki usia dewasa dan dinilai memiliki tingkat objektif yang tinggi. Seluruh responden menyatakan game BoMCleaN layak dijadikan media pembelajaran kebersihan lingkungan. 
Kualitas game BoMCleaN berdasarkan hasil kuesioner yang diberikan kepada responden terdapat pada Gambar 10. Game BoMCLeaN masih sering mengalami bug selama permainan berlangsung dinyatakan dengan $60 \%$ dari semua pendapat responden, alur permainan kurang menantang bernilai $20 \%$ dari pendapat responden, desain game kurang menarik sebesar $13 \%$ dan $7 \%$ pendapat dari responden menyatakan game sudah sangat baik ketika game dimainkan.

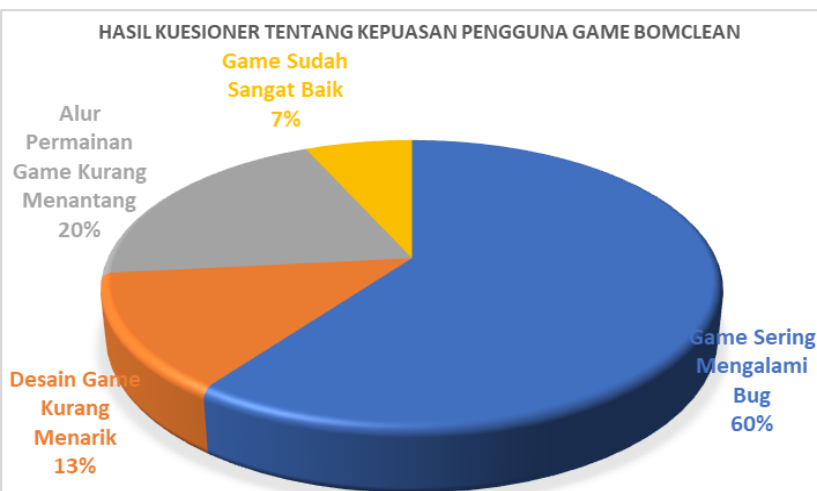

Gambar. 10 Hasil Kuesioner Tentang Kepuasan Pengguna Terhadap Game BoMCleaN

Responden memberikan berbagai saran untuk game BoMCleaN diantaranya perlunya peningkatan animasi dan desain yang lebih beragam, alur cerita yang lebih kompleks sehingga lebih menantang dan diperlukan server tersendiri untuk mengurangi bag selama permainan.

\section{KESIMPULAN DAN SARAN}

\section{A. Kesimpulan}

Berdasarkan game BoMCleaN yang telah dibuat, diperoleh beberapa kesimpulan sebagai berikut:

1. Game BoMCleaN sudah bisa dimainkan dengan beberapa pemain (multiplayer).

2. Game BoMCleaN dapat dimainkan oleh segala usia tetapi dikhususkan untuk pemain kategori anak-anak.

3. Game BoMCleaN sangat bergantung kepada kestabilan jaringan internet pemain.

4. Selama memainkan game BoMCleaN masih ditemukan beberapa bug antara lain saat pemain masuk kedalam room dimana karakter pemain akan terjebak diudara dan tidak terjatuh ketanah.

5. Game BoMCleaN memiliki desain karakter yang sederhana.

\section{B. Saran}

Saran untuk penelitian selanjutnya dalam rangka mengembangkan Game BoMCleaN yaitu:

1. Perlunya perbaikan untuk mengurangi bug ketika bermain.

2. Karakter pemain dalam game BoMCleaN bisa dibuat berbeda untuk setiap pemain.
3. Pada menu matchmaking ditambahkan pilihan level agar permainan lebih menarik, menantang dan tidak terkesan mudah.

\section{REFERENSI}

[1] Adiwikarta, Rendy. Pengembangan Permainan Video Endless Running Berbasis Android menggunakan Framework Game Development Life Cycle. Indonesia: KALBIScientia, ISSN: 23564393

[2] Arifin, Zaenal dkk. Membangun Game Petualangan Sejarah Peninggalan Sunan Kudus Berbasiskan Android. Indonesia: Prosiding SNATIF ke-2 Tahun 2015, ISSN: 978-602-1180-21-1

[3] Asrori, Lutfi. Perancangan dan Pembuatan Game Online "Penyelamatan Tawanan Perang" Berbasis HTML 5 untuk Penerapan Aplikasi Game Facebook Menggunakan Engine Construct 2. Indonesia: Jurnal DASI, September 2012, Vol 13 No.3

[4] Dewanto, I Joko, System Development Life Cycle dengan Beberapa Pendekatan, Indonesia: Jurnal FASILKOM, 1 Maret 2004, Vol 2 No.1

[5] Firmansyah, Yoki. Penerapan Model SDLC Waterfall dalam Pembuatan Sistem Informasi Akademik Berbasis Web Studi Kasus Pondok Pesantren Al-Habi Shaleh Kabupaten Kubu Raya, Kalimantan Barat. Indonesia: Jurnal Teknologi \& Manajemen Informatika, 2018, Vol 4 No.1

[6] Ibrahim, Muhammad Lutfi. Game Runner Berbasis Mobile yang Mengangkat Sejarah Indonesia. Indosia: e-proceeding, Agustus 2015, Vol 1 No. 2

[7] Kevin, Amelia Ananda, Aplikasi Game Berbahasa Inggris berbasis Macromedia Flash menggunakan metode waterfall. Indonesia:Simki-Techsain, Tahun 2017, Vol 01 No 07

[8] Martono, Kurniawan Teguh, Pengembangan Game dengan Menggunakan Game Engine Game Maker, Indonesia: Jurnal Sistem Komputer (JSISKOM), Mei 2015, vol 5 No 1, ISSN: 2087-4865, e-ISSN: 2252-3456

[9] Mahardhika, Alfian Putra. Pembuatan Game Android 2D Petualangan MR Kentang Menggunakan Unity. Indonesia: Jurnal Ilmiah Go Infotech, Desember 2015, Volume 21 No.2

[10] Mestadi, Walid dkk, An Assesment of Serious Games Technology: Toward an Architecture for Serious Games Design. Morocco: Hindawi, Internasional Journal of Computer Game Technology, Volume 2018, Articel ID 9834565

[11] Munadi Adi, Pembangunan Game Edukasi Mengenal PahlawanPahlawan Bangsa Indonesia. Indonesia: Jurnal Ilmiah dan Komputer (KOMPUTA), ISSN 2089-9033

[12] Putri, Bellia Dwi Cahya. Perancangan Aplikasi Permainan Multiplayer Gobak Sodor Berbasis Flash Dilingkup Jaringan Lokal. Indonesia: Jurnal Teknologi dan Sistem Komputer (JTSiskom), April 2016, Vol 4 No.2 e-ISSN: 2338-0403

[13] Purnomo, Fendi Aji. Pembuatan Game Edukasi "Petualangan Si Gembul" Sebagai Pembelajaran Pengenalan Daerah Solo Raya pada Anak. Indonesia: Jurnal Simetris, November 2016, Vol 7 No.2

[14] Rahman, Ridwan Arif. Pengembangan Game Edukasi Pengenalan Nama Hewan dan Habitatnya Dalam 3 Bahasa Sebagai Media Pembelajaran Berbasis Multimedia. Indonesia: Jurnal Algoritma Sekolah Tinggi Teknologi Garut, 2016, Vol 13 No. 1, ISSN: 2302-7339

[15] Singkoh, Robert Theophani, Perancangan Game FPS (First Person Shooter) Police Personal Training. Indonesia: E-Jurnal Teknik Elektro dan Komputer, Januari-Maret 2016, Vol 5 No. 1 ISSN: 2301-8402

[16] Soleh, Rachmat. Analisis Pengalaman Pengguna Permaianan Multiplayer Online Battle Arena (Moba) dengan Menggunakan Game Experience Questionnaire (GEQ) pada Game DOTA 2. Indonesia: Jurnal Pengembangan Teknologi Informasi dan Ilmu Komputer, September 2018, Vol 2 No.9 ISSN:3067-3076

[17] Utami, Reni dkk, Pembuatan Game Tradisional Dakon Multiplayer menggunakan Java, Indonesia: Indonsian Jurnal on Computer Science (IJCSS), ISSN: 1979-9390 